\title{
Gene expression concerning fatty acid and amino acid metabolism in Chlorella vulgaris cultured with antibiotics
}

\author{
Wenjing Wang ${ }^{1} \cdot$ Yanqing Sheng ${ }^{1}$
}

Received: 24 March 2020 / Revised: 16 July 2020 / Accepted: 6 August 2020 / Published online: 14 August 2020

(C) Springer-Verlag GmbH Germany, part of Springer Nature 2020

\begin{abstract}
The green alga Chlorella vulgaris has potential as a source of clean bioenergy with abundant metabolites and a high oil content, and antibiotics are often applied to remove bacteria from culture to obtain axenic algal strains. In this work, ceftazidime and gentamicin sulphate (GS) were added separately and in combination in the aseptic processing of C. vulgaris, and gene expression and metabolites were evaluated. The results showed that ceftazidime and GS effectively inhibited the proliferation of Cyanobacteria and Bacteroidetes, respectively. Overall, the effects of antibiotics on $C$. vulgaris differed: GS increased the algal concentration, whereas ceftazidime alone and in combination with GS treatment decreased the specific algal growth rate. Based on comparative transcription analysis, 5917 and 5899 differentially expressed genes (DEGs) were respectively upregulated and downregulated by ceftazidime, 963 and 3921 DEGs by GS, and 4532 and 1675 DEGs by the ceftazidime and GS combination. Pathway enrichment analysis showed that the downregulated DEGs in the ceftazidime groups were enriched in the fatty acid biosynthesis pathway but that the upregulated DEGs in the GS group were enriched in the fatty acid degradation pathway. Some pathways related to amino acid metabolism were markably influenced by antibiotic treatment. The results further indicated that antibiotics affected the intracellular concentration of fatty acids and amino acids in C. vulgaris. This study provides a new viewpoint regarding the response of $C$. vulgaris to antibiotics in the process of obtaining axenic algal strains.
\end{abstract}

\section{Key Points}

- Ceftazidime and gentamicin sulphate influenced bacterial proliferation.

- Downregulated differentially expressed genes mapped to the fatty acid biosynthesis pathway.

- Antibiotics affected intracellular concentrations of fatty acids and amino acids.

Keywords Amino acid metabolism $\cdot$ Axenic treatments $\cdot$ Fatty acid metabolism $\cdot$ Transcription analysis

\section{Introduction}

Algae are often considered a clean bioenergy source owing to their ability to accumulate and release proteins, polyunsaturated

Electronic supplementary material The online version of this article (https://doi.org/10.1007/s00253-020-10822-6) contains supplementary material, which is available to authorized users.

Yanqing Sheng

yqsheng@yic.ac.cn

1 Key Laboratory of Coastal Environmental Processes and Ecological Remediation, Yantai Institute of Coastal Zone Research, Chinese Academy of Sciences, 7 Chunhui Road, Yantai 264003, Shandong, China fatty acids, carbohydrates, pigments, nucleic acids, vitamins, and minerals (Sakarika and Kornaros 2019; Deviram et al. 2020). The green alga Chlorella vulgaris is an attractive algal species for this purpose due to its rapid growth and ease of cultivation (Chapman et al. 2019; Mathimani et al. 2019). Indeed, the intracellular substances of these species are regarded as commercially valuable for global fuel demand (Anto et al. 2020), and axenic cultivation of algae is crucial for scientific study or commercial application as biofuel. For processing, antibiotics are always applied to remove bacteria and obtain axenic strains (Barbosa et al. 2018; Vu et al. 2018). Although antibiotics have a high sterilizing capacity in algal culture, their effects on algal gene expression in aseptic processes remain unknown.

In algal cultivation systems, the bacterial cell count is generally 10-100 times higher than the algal cell count, reaching a 
density of $1 \times 10^{9}$ cells $\mathrm{mL}^{-1}$ (Wang et al. 2016), and the growth of algae is thus frequently inhibited by bacterial contamination (Lopez et al. 2019). Interactions between algae and symbiotic bacteria are complex. In general, algae aid bacterial growth by releasing dissolved organic carbon (Cirri and Pohnert 2019); conversely, bacteria can promote or inhibit algal proliferation (Cirri and Pohnert 2019; Lopez et al. 2019). In addition to nutrient competition, bacteria might inhibit algal productivity by diverting algal cellular resources from rapid growth to passive defence (Kazamia et al. 2012). Overall, bacteria have positive or negative effects on algal physiological and metabolic processes (Nguyen et al. 2019; Sun et al. 2020).

Many antibiotics, e.g. ampicillin, penicillin, azithromycin, kanamycin, and tetracycline, can achieve axenic culture. For example, Fu et al. (2017) determined the activity of 13 antibiotics and found that azithromycin, doxycycline, florfenicol, and oxytetracycline had significant toxic effects on algae. The physiological changes in algae depend on the concentration of antibiotics in culture (Dias et al. 2015). However, the inhibition efficiency or physiological change in bacteria and/or algae by these antibiotics in terms of the changes in gene expression and metabolic processes of algae during aseptic processing is still unclear. Although no remarkable changes in algal growth rates have been detected with some antibiotics (Wang et al. 2019), gene expression levels relating to algal metabolites might be influenced by antibiotics (Gordon and Pfleger 2018). The changes of gene expression levels would affect algal activity in the further application of axenic alga obtained by antibiotic treatment.

Selecting more appropriate antibiotics with clear interaction mechanisms on algae is important for algal axenic cultivation and further scientific research. Ceftazidime and gentamicin sulphate (GS) are two common broad-spectrum antibiotics used in humans. Ceftazidime and GS can inhibit infections by Pseudomonas, Proteus, Serratia, and Staphylococcus, which are also common strains of bacteria in algal culture (Wang and Sheng 2019; Wang et al. 2019). In this study, ceftazidime and GS were selected for application in aseptic cultivation of the unicellular green alga $C$. vulgaris to investigate effects of these on the gene expression and the ecological response of C. vulgaris. The objectives of this study were to (1) determine gene expression levels in $C$. vulgaris cells treated with ceftazidime, GS, and their combination and (2) examine amino acid and fatty acid biosynthesis and metabolism through de novo transcriptome and metabolite analyses.

\section{Materials and methods}

\section{Experimental design}

The unicellular green alga C. vulgaris FACHB-24 was acquired from the Freshwater Algae Culture Collection of the
Institute of Hydrobiology (Wuhan, China) and cultivated in a successional photobioreactor $(60 \mathrm{~cm}$ high and $5 \mathrm{~cm}$ diameter) containing $800 \mathrm{~mL}$ of BG11 medium (Sharma et al. 2018). The cells grew at $30^{\circ} \mathrm{C}$ under irradiance of $70 \mu \mathrm{mol}$ photons $\mathrm{m}^{-2} \mathrm{~s}^{-1}$ with continuous illumination provided by white fluorescent lamps. The algal density was measured under an Olympus CX23 light microscope (Olympus, Tokyo, Japan). The specific growth rates were calculated using the following formulas:

$\mu=\ln \left(N_{\mathrm{j}} / N_{\mathrm{i}}\right) /\left(t_{\mathrm{j}}-t_{\mathrm{i}}\right)$

where $\mu$ is the specific growth rate and $N_{\mathrm{j}}$ and $N_{\mathrm{t}}$ are the biomass at time $t_{\mathrm{j}}$ and time $t_{\mathrm{i}}$, respectively. For chlorophyll determination, algal cells in $5 \mathrm{~mL}$ of culture were collected by centrifugation and washed three times with phosphatebuffered saline $(\mathrm{pH}=7)$. Chlorophyll and carotenoids were extracted with $5 \mathrm{~mL}$ of a $90 \%$ acetone solution for $24 \mathrm{~h}$ at $4{ }^{\circ} \mathrm{C}$, after which the solution was centrifuged at $10,000 \times g$ for $15 \mathrm{~min}$. The absorbance of the supernatant was measured with a spectrophotometer (TU1901, Beijing Purkinje General Instrument Co Ltd., Beijing, China) at $470 \mathrm{~nm}, 646.8 \mathrm{~nm}$, and $663.2 \mathrm{~nm}$. Quantitative determination of chlorophyll $a$ and chlorophyll $b$ and carotenoids was performed as reported by $\mathrm{He}$ et al. (2018).

In pre-experiments, $0-30 \mathrm{mg} \mathrm{L}^{-1}$ ceftazidime, $0-$ $65 \mathrm{mg} \mathrm{L}^{-1} \mathrm{GS}$, and their combination were added to C. vulgaris cultures to evaluate effects on growth (Supplemental Fig. S1 and Fig. S2); $10 \mathrm{mg} \mathrm{L}^{-1}$ ceftazidime and $25 \mathrm{mg} \mathrm{L}^{-1} \mathrm{GS}$ were observed to have a minor effect on the growth rate of $C$. vulgaris but a high inhibition effect on bacteria. C. vulgaris samples were treated with different concentrations of ceftazidime, GS, and their combined solutions based on the results of the pre-experiments. An algal culture without antibiotic addition was used as the control. All treatments (experiments and control) were conducted with six biological replicates.

\section{Changes in the symbiotic bacterial community}

\section{Bacterial abundance}

Determination of bacterial abundance and composition was performed in triplicate. The bacterial count was determined by 4',6-diamidino-2-phenylindole (DAPI) staining with an Axio Observer A1 inverted fluorescence microscope (Carl Zeiss, Oberkochen, Germany). Briefly, $1 \mathrm{~mL}$ of sample was added to a sterilized glass tube containing $1 \mathrm{~mL}$ of $10 \mu \mathrm{g} \mathrm{L}^{-1}$ concentration of DAPI and $1 \mathrm{~mL}$ of Triton X-100 (0.1\%), and the mixture was homogenized for $30 \mathrm{~s}$ and allowed to stand in the dark for $10 \mathrm{~min}$ prior to filtration through $0.22-\mu \mathrm{m}$ black polycarbonate filters (GSWP02500, Millipore, Burlington, MA, USA). The filters were examined with UV light using 
an epifluorescence microscope and an oil immersion objective. Each field was adjusted to 50-200 cells, and 30 fields were counted for each sample. The results are expressed as cells per millilitre.

\section{Bacterial community composition}

The culture was filtered through $0.45-\mu \mathrm{m}$ filter membranes (HABG047S6, Millipore, Burlington, MA, USA) to obtain filtrates containing bacteria, which were passed through a 0.22- $\mu \mathrm{m}$ membrane (GVWP04700, Millipore, Burlington, MA, USA) to collect the bacterial cells. The $0.22-\mu \mathrm{m}$ filter membrane with bacterial cells was cut into small pieces and placed in a sterile tube, and bacterial DNA was extracted with a Bacterial DNA Isolation Kit according to the manufacturer's protocol (Qiagen, Hilden, Germany). The extracted DNA was subsequently measured using a NanoDrop ND-1000 spectrophotometer (ThermoFisher Scientific, Waltham, MA, USA) and amplified by polymerase chain reaction with the following primers targeting the V4-V5 region of bacterial $16 \mathrm{~S}$ ribosomal DNA: 515F (5'-GTGCCAGCMGCCGCGG-3') and 907R (5'-CCGTCAATTCMTTTRAGTTT-3'). The PCR products were purified using the DNA gel extraction kit (ThermoFisher Scientific, Waltham, MA, USA), and a DNA library was constructed using an Ion Plus Fragment Library Kit 48 rxns (ThermoFisher Scientific, Waltham, MA, USA). After DNA library quantification, the bacterial sequences were analysed using an IonS5TMXL sequencing platform (ThermoFisher Scientific, Waltham, MA, USA). Lowquantity reads were removed by Cutadapt (V1.9.1). Sample data were split according to barcode, and the barcode and primer sequences were removed to obtain raw reads (Rognes et al. 2016). The raw reads were BLAST searched, and adapter sequences were removed to obtain clean reads. Uparse V7.0.1001 software was employed to perform quality control and to cluster sequences into operational taxonomic units (OTU) (Haas et al. 2011). Species were annotated using the Mothur method and the SSU rRNA database (Edgar 2013). MUSCLE version 3.8.31 was used to BLAST search the sequences to determine relationships among all OTU sequences (Quast et al. 2013). Alpha diversity was analysed using Qiime version 1.9.1 (Caporaso et al. 2010).

\section{RNA isolation, library preparation, and sequencing}

After treatments, samples were filtered $(5000 \times g, 15 \mathrm{~min})$, washed three times with $\mathrm{K}_{3} \mathrm{PO}_{4}$ buffer $(\mathrm{pH} 7)$ to remove bacterial cells, and then stored in liquid nitrogen for RNA extraction in triplicate. Total RNA was extracted with TRIzol (Invitrogen, Carlsbad, CA, USA), treated with RNase-free DNase I (Takara Biomedical Technology (Beijing) Co. Ltd., Beijing, China), and purified using a NanoPhotometer ${ }^{\circledR}$ spectrophotometer (Implen, Westlake Village, CA, USA). The
RNA concentration was determined using a Qubit ${ }^{\circ} 2.0$ fluorometer (Life Technologies, Carlsbad, CA, USA), and the integrity was assessed using an RNA Nano 6000 assay kit with an Agilent 2100 Bioanalyser (Agilent Technologies, Palo Alto, CA, USA). RNA library preparation was conducted by the Novogene Company (Beijing, China). The twelve raw data, including biological replicates, were submitted to the Sequence Read Archive of the NCBI database. The accession numbers of the data are from SRR9673436 to SRR9673447.

Sequencing libraries were prepared using the NEBNext ${ }^{\circledR}$ Ultra $^{\text {TM }}$ RNA library prep kit (New England Biolabs, Ipswich, MA, USA) for the Illumina platform. Briefly, mRNA was purified using poly-T oligo-attached magnetic beads and then fragmented using divalent cations under elevated temperature. cDNA was then synthesized, and the library fragments were purified using the AMPure XP system to obtain cDNA fragments of length $250-300 \mathrm{bp}$. Before polymerase chain reaction, USER Enzyme (New England Biolabs, Ipswich, MA, USA) was added to the size-selected, adaptor-ligated cDNA and incubated at $37^{\circ} \mathrm{C}$ for $15 \mathrm{~min}$ and then $95{ }^{\circ} \mathrm{C}$ for $5 \mathrm{~min}$. The products were purified, and the library quality was assessed using the Agilent Bioanalyser 2100 system. Raw data in FASTQ format were processed using in-house Perl scripts (Xu et al. 2016). Clean reads were obtained by removal of reads containing the adapter and poly-N as well as lowquality reads from the raw data. Base call accuracy was estimated to be $99.9 \%$ with a score of 30 and $99 \%$ with a score of 20. The percentage of GC was calculated as the GC ratio of sequences. All downstream analyses were performed using clean high-quality data. After transcriptome assembly, gene functions were annotated using seven databases: the NCBI non-redundant protein sequence (NR), NCBI non-redundant nucleotide sequence (NT), Protein Family (PFAM), Clusters of Orthologous Groups of Proteins (KOG/COG), Protein sequence (Swiss-Prot), Kyoto Encyclopedia of Genes and Genomes Ortholog Database (KEGG), and Gene Ontology (GO) databases.

\section{Analysis of differentially expressed gene}

A $q$ value of $<0.005$ and $\log _{2}$ (fold change) of $>1$ was set as the threshold for significant differential expression. The analysis of DEG in C. vulgaris between the control and treatment groups was performed using the DESeq R package (v1.10.1) (Gao et al. 2018). DESeq was employed to provide statistical analysis for determining DEGs using a model based on a negative binomial distribution. Benjamini and Hochberg's approach was used to analyse $p$ values, and genes with an adjusted $p$ value of $<0.05$ by DESeq were considered differentially expressed. KEGG is utilized as a database resource for understanding gene functions and biological system utilities (Kanehisa et al. 2007), including cells, organisms, and ecosystems, from molecular-level information, especially for 
large-scale molecular datasets generated by genome sequencing and other high-throughput experimental technologies (http://www.genome.jp/kegg/). In addition, KOBAS software was applied to test statistical enrichment of DEGs in KEGG pathways (Mao et al. 2005).

\section{Determination of medium-long-chain fatty acid contents}

Samples for fatty acid determination were collected by centrifugation $(5000 \times g, 15 \mathrm{~min})$ and washed with phosphatebuffered saline ( $\mathrm{pH}=7.0)$. Approximately $500 \mathrm{mg}$ of sample in triplicate were placed in a $2-\mathrm{mL}$ glass centrifuge tubes with $2 \mathrm{~mL}$ of a $\mathrm{CH}_{3} \mathrm{OH}-\mathrm{CHCl}_{3}$ mixture addition, and the tubes were placed in an ultrasonic bath for $30 \mathrm{~min}$. The supernatants were transferred into new centrifuge tubes, and $1 \mathrm{~mL}$ of a $\mathrm{H}_{2} \mathrm{SO}_{4}-\mathrm{MeOH}$ solution was added for $30 \mathrm{~min}$ in a water bath at $80{ }^{\circ} \mathrm{C}$ to achieve methyl esterification (Breuer et al. 2013). The samples were extracted with n-hexane, washed with ultrapure water, and transferred to sampling bottles. Methyl salicylate was used as an interior label for fatty acid determination.

Thirty-four Nu-Chek-Prep fatty acid methyl esters (NuChek-Prep. Inc., Elysian, MN, USA), including hexanoic acid (C6:0), octanoic acid (C8:0), decanoic acid (C10:0), undecanoic acid (C11:0), dodecanoic acid (C12:0), tridecylic acid (C13:0), myristic acid (C14:0), myristoleic acid (C14:1), pentadecanoic acid (C15:0), cis-10-pentadecenoic acid (C15:1), palmitic acid (C16:0), palmitoleic acid (C16:1), heptadecanoic acid (C17:0), cis-10-heptadecenoic acid (C17:1), stearic acid (C18:0), oleic acid (C18:1N9), linoleic acid (C18:2N6), $\alpha$-linolenic acid (C18:3N3), $\gamma$-linolenic acid (C18:3 N6), arachidic acid (C20:0), cis-11-eicosenoic acid (C20:1), cis-11,14-eicosadienoic acid (C20:2), cis-11,14,17eicosatrienoic acid (C20:3N3), cis-8,11,14-eicosatrienoic acid (C20:3N6), arachidonic acid (C20:4N6), cis-5,8,11,14,17eicosapentaenoic acid (C20:5N3), heneicosanoic acid (C21:0), behenic acid (C22:0), erucic acid (C22:1N9), cis13,16-docosadienoic acid (C22:2), tricosanoic acid (C23:0), tetracosanoic acid (C24:0), cis-4,7,10,13,16,19docosahexaenoic acid (C22:6N3), and nervonic acid (C24:1), were selected as the standard solution for standard curve generation. The standard solution of mixed Nu-ChekPrep fatty acid methyl esters was set to nine concentrations: $1 \mathrm{mg} \mathrm{L}{ }^{-1}, 5 \mathrm{mg} \mathrm{L}^{-1}, 10 \mathrm{mg} \mathrm{L}^{-1}, 25 \mathrm{mg} \mathrm{L}^{-1}, 50 \mathrm{mg} \mathrm{L}^{-1}$, $100 \mathrm{mg} \mathrm{L}^{-1}, 250 \mathrm{mg} \mathrm{L}^{-1}, 500 \mathrm{mg} \mathrm{L}^{-1}$, and $1000 \mathrm{mg} \mathrm{L}^{-1}$. Two ratios $2.67 \%$ and $5.26 \%$ of each component to total concentration were set in the standard solutions, respectively. The chromatographic peak area and retention time were extracted using MSD ChemStation Data Analysis (Agilent Technologies International Ltd., Palo Alto, CA, USA). Medium-long-chain fatty acids were quantified based on standard curves using an Agilent 6890N/5975B gas chromatograph-mass spectrometer (Agilent Technologies, Palo Alto, CA, USA) with an Agilent HP-INNOWAX column $(30 \mathrm{~m} \times 0.25 \mathrm{~mm}$ ID $\times 0.25 \mu \mathrm{m})$. Quality control samples were analysed and set at a certain interval in the sample queue to monitor the system stability.

\section{Amino acid determination}

For amino acid profiling, $1 \mathrm{~mL}$ of methanol/acetonitrile/water $(2: 2: 1, \mathrm{v} / \mathrm{v} / \mathrm{v})$ was added to $500 \mathrm{mg}$ of homogenized sample with six replicates. The mixture was sonicated for $20 \mathrm{~min}$, and then proteins were precipitated at $-20{ }^{\circ} \mathrm{C}$ for $1 \mathrm{~h}$. After centrifugation, the supernatant was dried under vacuum at a low temperature. The residue was resuspended in $100 \mu \mathrm{L}$ of an acetonitrile/water solution and centrifuged $(12,000 \times g$, $15 \mathrm{~min}$ ), and the supernatant was used for further analysis with an Agilent 1290 Infinity LC (Agilent Technologies, Palo Alto, CA, USA) and a 5500 QTRAP MS system (AB Sciex, Darmstadt, Germany). The detection conditions were the same as those of a previous report (Bai et al. 2018). Chromatographic peak areas and retention times were extracted using MultiQuant software (AB Sciex, Framingham, MA, USA). Both amino acid and derivative standards were analytical reagents (Sigma-Aldrich Corporation, Burlington, MA, USA) and were used as the standards to verify the identity of chromatographic peaks. A $p$ value of $<0.05$ identified by DESeq indicated significantly differential amino acid production between the treatment and control groups.

\section{Results}

\section{Diversity and abundance of the bacterial community}

In the cultures with ceftazidime and GS, bacterial abundances decreased by $\sim 80 \%$, and bacterial diversities also declined, with the combination of ceftazidime and GS having the highest inhibitory effect on bacterial growth (Fig. 1a). The mean raw reads in the $\mathrm{CK}$, ceftazidime, GS, and combined ceftazidime and GS groups were $84,546,84,966,81,825$, and 85,692 , respectively (Table 1 ). The results showed that antibiotics reduced both bacterial community richness and diversity. GS treatment resulted in higher Chaol and ACE values than those in the ceftazidime group. The combined GS and ceftazidime group presented the highest Shannon index value, followed by the ceftazidime group and the GS groups. Seven phyla were identified among the symbiotic bacterial communities (Fig. 1b). Bacteroidetes was the most abundant bacterial phylum, accounting for an average of $38 \%$ of the total sequences in the control, followed by Proteobacteria (33\%), Cyanobacteria (5\%), Armatimonadetes (0.3\%), and Planctomycetes $(0.2 \%)$. The relative abundances of Bacteroidetes, Proteobacteria, and Cyanobacteria in the 


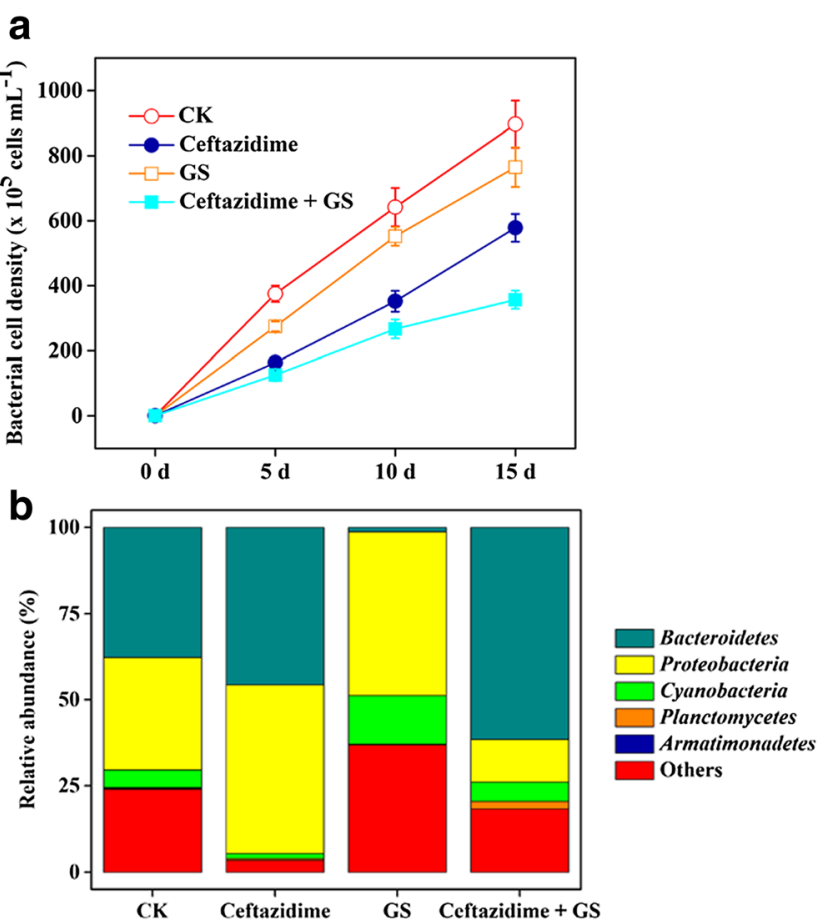

Fig. 1 Abundance and composition of symbiotic bacteria in algal culture. "Others" included phyla with unclassified bacteria and phyla with a relative abundance of $<0.01 \%$. (a) Effects of antibiotics on cell density of symbiotic bacteria. (b) Changes of symbiotic bacteria community with antibiotic addition

ceftazidime group were $45.6 \%, 48.95 \%$, and $1.44 \%$, respectively. However, the abundances of the above-mentioned phyla were $1.28 \%, 47.45 \%$, and $14.16 \%$ in the GS group and $62.13 \%, 11.32 \%$, and $5.83 \%$ in the combined ceftazidime and GS groups, respectively. Among all treatments, Proteobacteria, Proteobacteria, and Bacteroidetes exhibited the highest relative abundances in the ceftazidime group, followed by those in the GS group and the combined ceftazidime and GS groups.

\section{Variations in algal growth rates}

Ceftazidime and GS caused different changes in the specific growth rate of $C$. vulgaris, and the cell density was closely related to the concentration of these antibiotics. Compared with the control, ceftazidime reduced algal concentration, and GS increased algal growth; the specific growth rate was decreased by the combination of ceftazidime and GS (Fig. 2). After cultivation for 15 days, ceftazidime reduced algal growth by $14.5 \%$, GS led to a $12.7 \%$ increase in algae, and the combination of both antibiotics resulted in slight inhibition of 3.4\%. Quantitative determinations of $\mathrm{Chl} a, \mathrm{Chl} b$, and carotenoids were performed at 15 days, with concentrations decreasing after culture with ceftazidime or GS. The highest contents of $\mathrm{Chl} a, \mathrm{Chl} b$, and carotenoids were in the samples treated with both ceftazidime and GS, at $3.81 \pm 0.13 \mu \mathrm{g} \mathrm{mL}^{-1}, 2.46 \pm 0.14 \mu \mathrm{g} \mathrm{mL}^{-1}$, and $1.56 \pm$ $0.13 \mu \mathrm{g} \mathrm{mL}^{-1}$, respectively.

\section{Annotation of transcriptional sequences}

A total of $629,569,872$ reads were mapped to the assembled genome; $618,243,408$ clean reads and $95.22 \mathrm{G}$ bases with a $66 \%$ GC content were detected. Base-call accuracies of $92 \%$ for Q scores of 30 and $97 \%$ for Q scores of 20 were obtained. Split joints were used to obtain reference sequences for subsequent analyses with Trinity (v2.4.0) (Table 2), and the assembly ultimately shows an average length of 2027 bp, N50 of 3026 bp, and N90 of 1010 bp (Supplemental Fig. S3). Seven libraries were constructed for gene function annotation, and 58,415 unigenes were annotated and matched to $63.23 \%, 40.64 \%, 63 \%, 29.71 \%$, $48.02 \%, 25.37 \%$, and $63 \%$ of the sequences in the NR, NT, PFAM, KOG/COG, Swiss-Prot, KEGG, and GO databases, respectively (Fig. 3a). The percentage of homologous sequences matched in the $\mathrm{Nr}$ database between Chlorella and closely related algae is shown in Fig. 3b. Due to the lack of genomic information for $C$. vulgaris FACHB-24, the results of analysis using the sequences for algae were diverse. The top hits included Chlorella sorokiniana (32.9\%), Micractinium conductrix (14.6\%), and Chlorella variabilis (4.9\%). Genes were mapped to KEGG pathways and assigned GO terms. Genes related to cell processes (913 genes, A), environmental information processing (561 genes, B), genetic information processing (3508 genes, C), metabolism (5764 genes, D), and organismal systems (180 genes, E) were annotated based on the KEGG database (Fig. 4). The following GO results were obtained:

Table 1 Alpha diversity index of bacterial communities

\begin{tabular}{|c|c|c|c|c|c|c|c|}
\hline \multirow[t]{2}{*}{ Samples } & \multirow[t]{2}{*}{ Raw reads } & \multirow[t]{2}{*}{ Effective (\%) } & \multirow[t]{2}{*}{ Good's coverage GC } & \multicolumn{2}{|c|}{ Community richness } & \multicolumn{2}{|c|}{ Community diversity } \\
\hline & & & & Chao1 & $\mathrm{ACE}$ & Shannon & Simpson \\
\hline CK & $84,546 \pm 793$ & $94.95 \pm 4.18$ & 1 & $58.28 \pm 5.82$ & $54.84 \pm 4.65$ & $3.90 \pm 0.03$ & $0.66 \pm 0.00$ \\
\hline Ceftazidime & $84,966 \pm 663$ & $94.43 \pm 3.35$ & 1 & $52.17 \pm 2.25$ & $53.82 \pm 2.23$ & $2.54 \pm 0.16$ & $0.72 \pm 0.18$ \\
\hline GS & $81,825 \pm 126$ & $97.95 \pm 0.24$ & 1 & $52.52 \pm 1.42$ & $53.98 \pm 1.28$ & $2.25 \pm 0.07$ & $0.68 \pm 0.17$ \\
\hline Ceftazidime + GS & $85,692 \pm 283$ & $93.64 \pm 3.62$ & 1 & $51.50 \pm 4.83$ & $52.19 \pm 4.54$ & $2.61 \pm 0.16$ & $0.65 \pm 0.06$ \\
\hline
\end{tabular}


Fig. 2 Physiological changes in C. vulgaris after antibiotic incubation. All data are shown as the mean value ( \pm S.E.) of three biological replicates. (a) Specific growth rate of $C$. vulgaris in the various treatments. In b-d, effects of antibiotics on the contents of $\mathrm{Chl} a$, Chl $b$, and carteniods of C. vulgaris, respectively
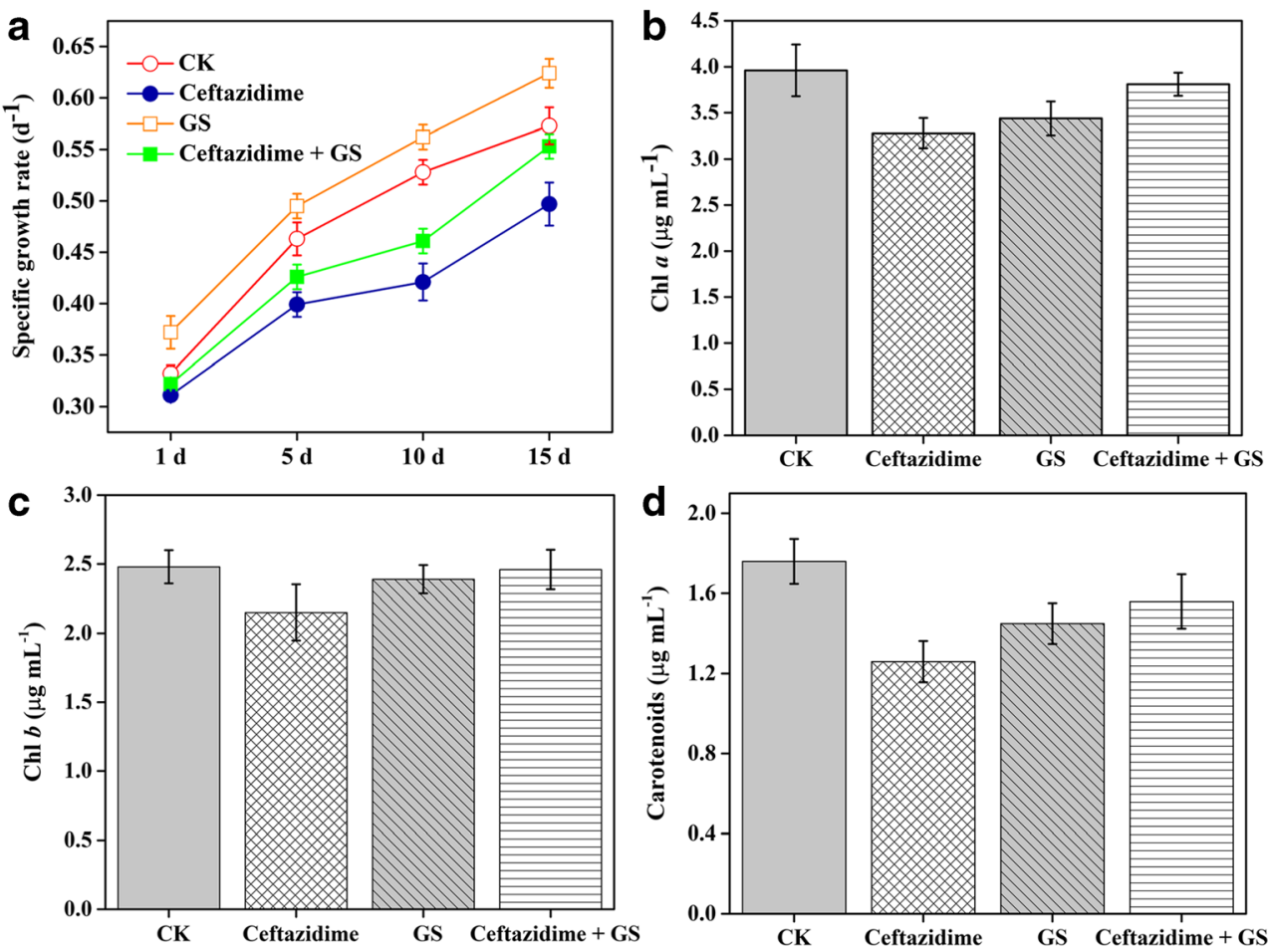

biological process (31), cellular component (15), and molecular function (9) (Supplemental Fig. S4).

\section{DEG analysis}

Among the differentially expressed genes, 5917 unigenes were upregulated and 5899 unigenes downregulated in the ceftazidime group compared with the control group; 963 unigenes were upregulated and 3921 unigenes downregulated in the GS group (Fig. 5), and 4532 unigenes were upregulated and 1675 unigenes downregulated in the combined ceftazidime and GS group. According to pathway enrichment analysis, the upregulated DEGs were enriched in pathways of
DNA damage and DNA replication in all groups. In the ceftazidime group, enrichment in the pathways of linoleic acid metabolism was found for upregulated DEGs (Supplemental Fig. S5a), whereas downregulated DEGs were enriched in pathways of several amino acid metabolism pathways, including valine, leucine, and isoleucine biosynthesis; pyruvate metabolism; and glycine, serine, and threonine metabolism (Supplemental Fig. S5b). For the GS group, upregulated DEGs were enriched in pathways of fatty acid degradation; valine, leucine, and isoleucine degradation; pyrimidine metabolism; nucleotide excision repair; and mismatch repair (Supplemental Fig. S5c); downregulated DEGs were enriched in the pathway of fatty acid biosynthesis (Supplemental Fig.
Table 2 Summary quality measurement details of RNA samples

\begin{tabular}{lllllll}
\hline Sample & Raw reads & Clean reads & Clean bases & Q20 (\%) & Q30 (\%) & GC (\%) \\
\hline CK_1 & $65,560,510$ & $65,783,116$ & $9.22 \mathrm{G}$ & 97.38 & 92.15 & 66.48 \\
CK_2 & $65,566,066$ & $65,785,486$ & $9.87 \mathrm{G}$ & 97.31 & 92.98 & 66.38 \\
CK_3 & $65,568,824$ & $65,784,994$ & $9.25 \mathrm{G}$ & 97.16 & 92.68 & 66.6 \\
Ceftazidime_1 & $69,956,786$ & $68,664,226$ & $10.16 \mathrm{G}$ & 97.44 & 93.23 & 66.52 \\
Ceftazidime_2 & $69,969,134$ & $68,666,786$ & $10.92 \mathrm{G}$ & 97.43 & 93.23 & 66.6 \\
Ceftazidime_3 & $69,971,442$ & $68,660,056$ & $10.3 \mathrm{G}$ & 97.52 & 93.43 & 66.48 \\
GS_1 & $74,328,142$ & $71,630,660$ & $11.77 \mathrm{G}$ & 97.52 & 93.43 & 66.87 \\
GS_2 & $74,321,748$ & $71,634,022$ & $11.75 \mathrm{G}$ & 97.52 & 93.43 & 66.92 \\
GS_3 & $74,327,220$ & $71,634,062$ & $11.98 \mathrm{G}$ & 97.37 & 93.14 & 66.72 \\
(Ceftazidime + GS)_1 & $68,926,966$ & $66,343,704$ & $9.95 \mathrm{G}$ & 97.35 & 93.01 & 66.46 \\
(Ceftazidime + GS)_2 & $69,180,328$ & $66,777,618$ & $10.02 \mathrm{G}$ & 97.36 & 93.08 & 66.43 \\
(Ceftazidime + GS)_3 & $70,235,122$ & $67,476,640$ & $10.12 \mathrm{G}$ & 97.52 & 93.47 & 66.47 \\
\hline
\end{tabular}




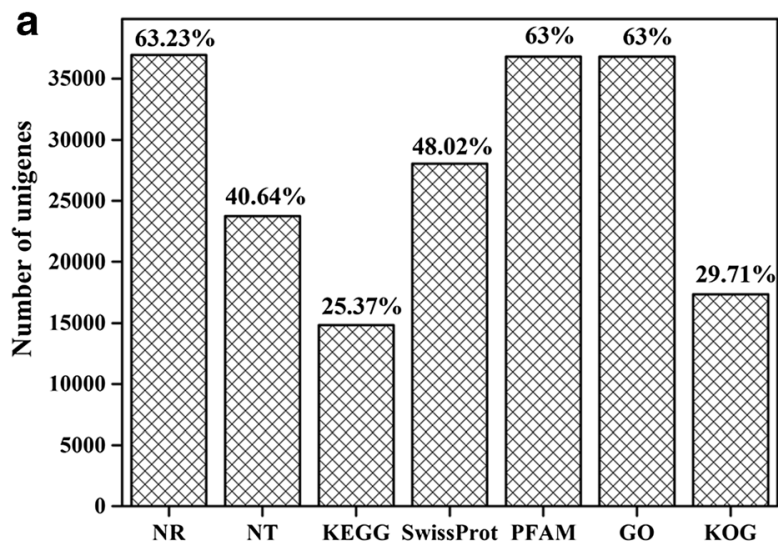

b

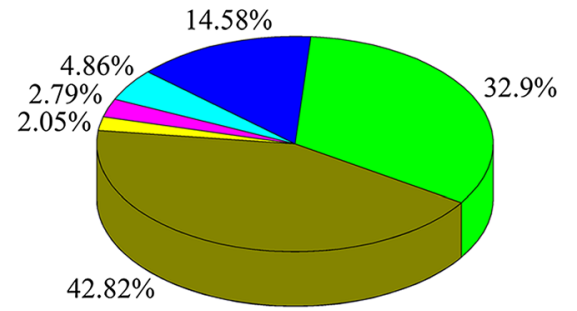

\section{Chlorella sorokiniana Micractinium conductrix Chlorella variabilis $\square$ Klebsormidium nitens Guillardia theta Others}

Fig. 3 Information on transcriptional sequences. (a) The NR, NT, PFAM, KOG/COG, Swiss-Prot, KEGG, and GO databases were used for Chlorella gene annotation. (b) Species distribution for homologous Chlorella sequences

S5d). Regarding the combined ceftazidime and GS group, upregulated DEGs showed enrichment in pathways of pyruvate metabolism, tryptophan metabolism, and fatty acid degradation (Supplemental Fig. S5e) and downregulated DEGs in pathways of fatty acid biosynthesis, porphyrin and chlorophyll metabolism, and arginine and proline metabolism (Supplemental Fig. S5f).

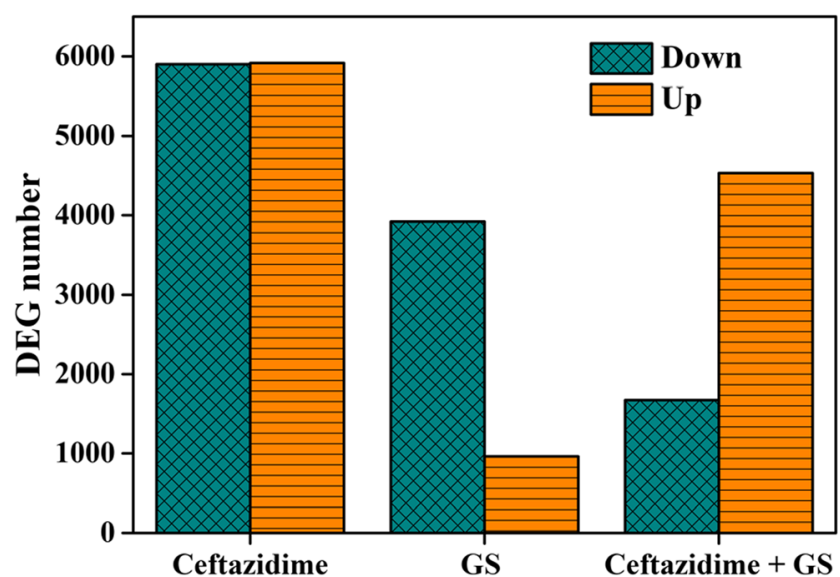

Fig. 5 Total number of genes with significant differential expression

\section{Fatty acid and amino acid metabolism transcript information}

Fourteen pathways of fatty acid metabolism were annotated in the KEGG database. As shown in Fig. 6a, 966 genes were annotated as involved in fatty acid metabolism. The detailed genes and pathways are as follows: arachidonic acid metabolism (Ara-, 46 genes); unsaturated fatty acid biosynthesis (Bio-, 80 genes); cutin, suberin, and wax biosynthesis (Cut-, 3 genes); ether lipid metabolism (Eth-, 54 genes); fatty acid biosynthesis (Fat-B, 75 genes); fatty acid degradation (Fat-D, 109 genes); fatty acid elongation (Fat-E, 29 genes); glycerolipid metabolism (Gly-L, 126 genes); glycerophospholipid metabolism (Gly- $P, 188$ genes); linoleic acid metabolism (Lin-, 13 genes); sphingolipid metabolism (Sph-, 60 genes); steroid biosynthesis (Ste-, 79 genes); ketone body synthesis and degradation (syn, 52 genes); and $\alpha$ linolenic acid metabolism (alp-, 52 genes). Compared with those in the control, 79 genes and 74 genes were
Fig. 4 Proportion of genes (\%) annotated by the KEGG database. $\mathrm{A}$, cell processes; $\mathrm{B}$, environmental information processing; $\mathrm{C}$, genetic information processing; $\mathrm{D}$, metabolism; E, organismal systems

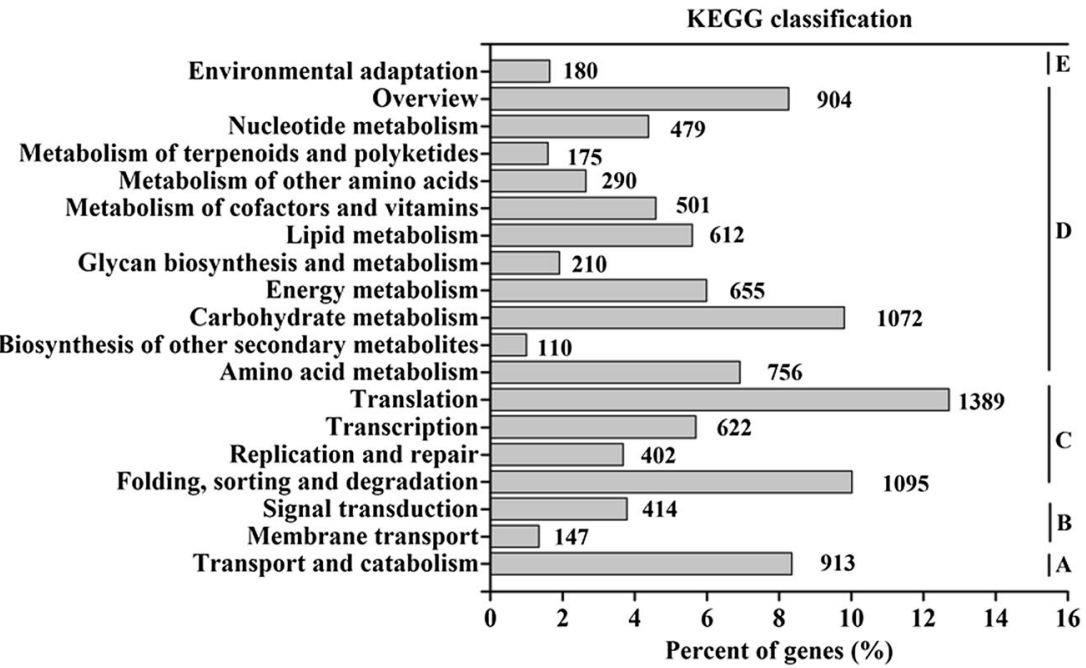


Fig. 6 Annotated genes and DEGs involved in lipid acid metabolism. (a) Changes of gene number of lipid acid metabolism in $C$. vulgaris under antibiotic addition. (b-d) The number of DEGs in ceftazidime, GS, and the combined ceftazidime and GS groups, respectively
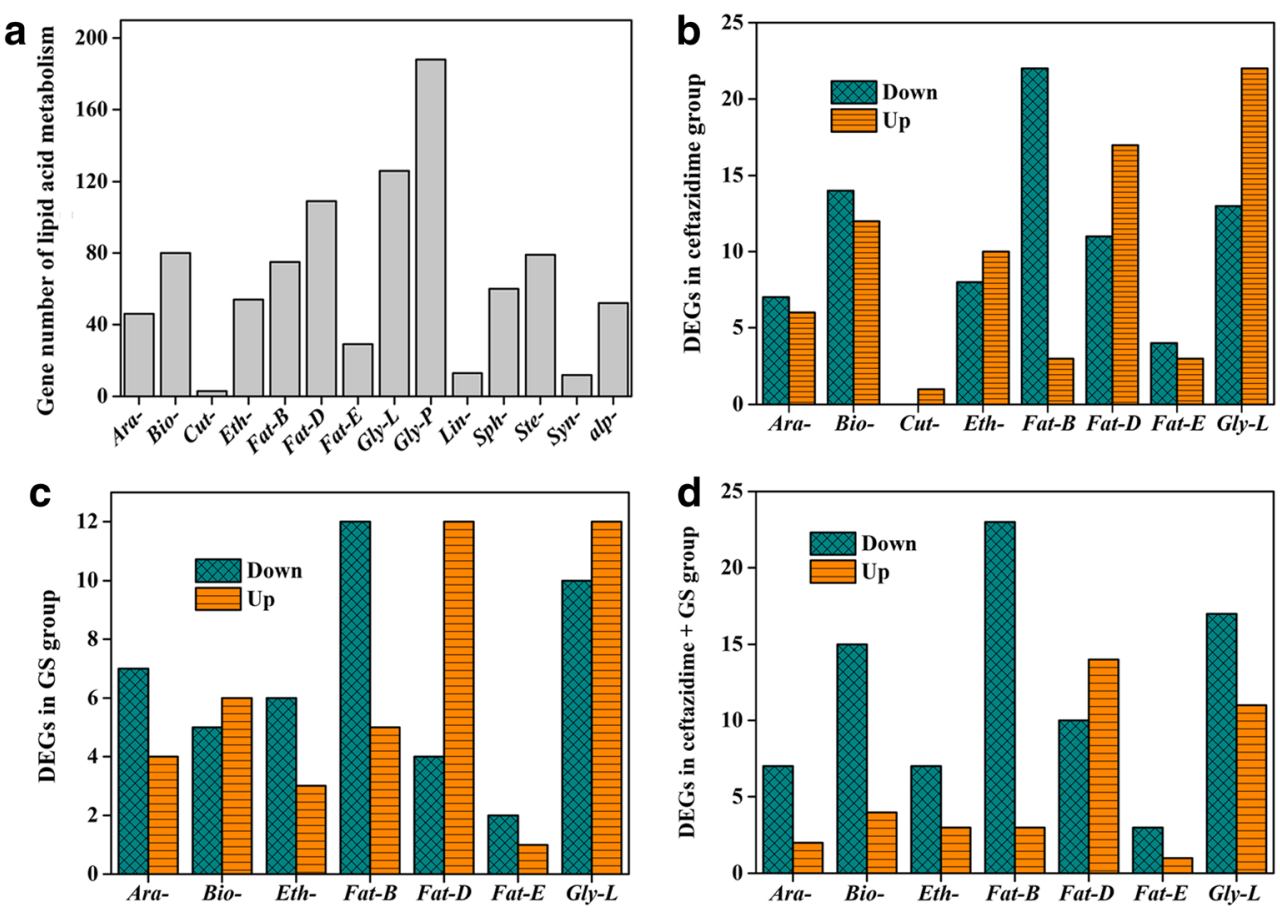

downregulated and upregulated in the ceftazidime group, respectively (Fig. 6b). In the GS group, 46 genes were downregulated and 43 genes upregulated compared with the control (Fig. 6c). In the combined ceftazidime and GS group, 82 and 38 genes were downregulated and upregulated, respectively, compared with the control (Fig. 6d). Furthermore, pathways of arachidonic acid metabolism and $\alpha$-linolenic acid metabolism were enriched according to KEGG pathway analysis (Supplemental Figs. S6 and S7). With regard to arachidonic acid metabolism, the $T g l 4$ gene, which is involved in lysophosphatidic acid acyltransferase or arachidonic acid synthesis, was upregulated. However, other genes involved in arachidonic acid synthesis, including GpX, Ggt1_5, and Lta4H, were downregulated (Supplemental Table S1). The gene which encodes EC 3.1.14 and the gene FatA for EC 3.1.1.32 involved in $\alpha$-linolenic acid synthesis were upregulated. The gene $M f p 2$ for peroxisomal fatty acid betaoxidation multifunctional protein and the $A c X$ gene for peroxisomal acyl-coenzyme A oxidase 3 were downregulated in the combined ceftazidime and GS group. The products of gene $M f p 2$ and $A c X$ are responsible for transformation of $\alpha$ linolenic acid into 3-hydroxyacyl-CoA dehydrogenase (3oxo-OPC4-CoA) in the $\alpha$-linolenic acid metabolism.

According to KEGG analysis, the DEGs were enriched in several pathways of amino acid metabolism (Supplemental Table S2). Specifically, upregulated DEGs showed enrichment in pathways of arginine and proline metabolism; cysteine and methionine metabolism; glycine, serine, and threonine metabolism; glutathione metabolism; and alanine, aspartate, and glutamate metabolism. In contrast, downregulated DEGs were enriched in pathways of valine, leucine, and isoleucine degradation; glutathione metabolism; cysteine and methionine metabolism; and beta-alanine metabolism. Therefore, antibiotics might have various influences on different amino acid production pathways, resulting in redirections of amino acid metabolisms.

\section{Fatty acid quantification}

The contents of medium-long-chain fatty acids in algal extracts were determined under optimal conditions (Fig. 7). The total concentration of fatty acids decreased in the treatment groups

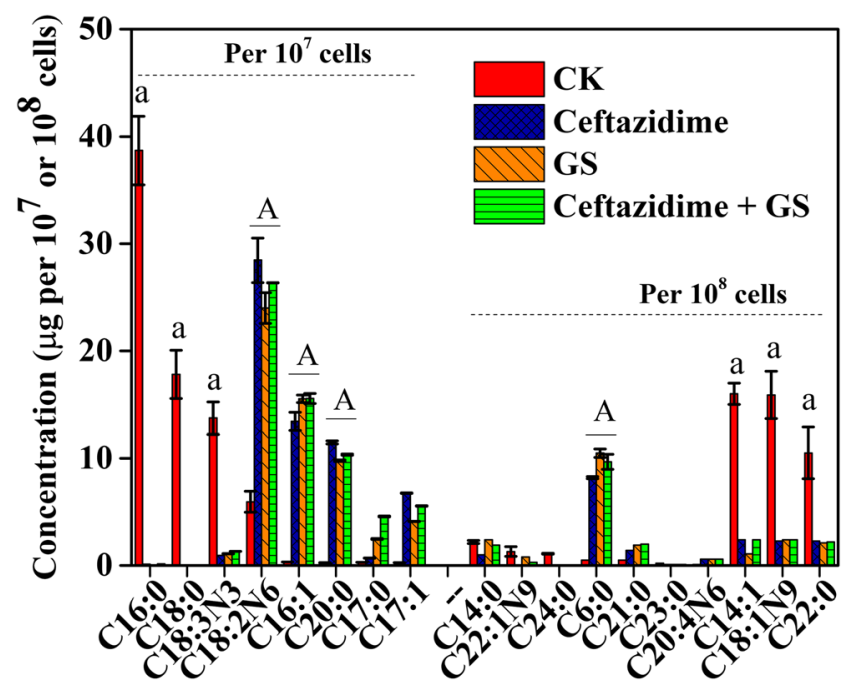

Fig. 7 Concentrations of medium-long-chain fatty acids in $C$. vulgaris. "A" or "a" indicates a significant $(p<0.05)$ increase or decrease, respectively, in fatty acid concentration between the treatment and control groups 
compared with the controls. A total of $0.048 \mathrm{pg}$ cells $^{-1}$ of medium-long-chain fatty acids was observed in the control, which was higher than that in the ceftazidime $\left(0.018 \mathrm{pg}\right.$ cells $\left.{ }^{-1}\right)$, GS $\left(0.022 \mathrm{pg}^{-1}\right.$ cell $\left.^{-1}\right)$, and combined ceftazidime and GS $\left(0.022 \mathrm{pg}\right.$ cells $\left.^{-1}\right)$ groups. The palmitic acid (C16:0), stearic acid (C18:0), $\alpha$-linolenic acid (C18:3N3), myristoleic acid (C14:1), oleic acid (C18:1N9), and behenic acid (C22:0) levels in the control group were also higher than those in the treatment groups. Nevertheless, linoleic acid (C18:2N6), palmitoleic acid (C16:1), arachidic acid (C20:0), and hexanoic acid (C6:0) were more abundant in the treatment groups than in the control. There were no remarkable changes in concentrations of the fatty acids heptadecanoic acid (C17:0), cis-10-heptadecenoic acid (C17:1), myristic acid (C14:0), erucic acid (C22:1N9), tetracosanoic acid (C24:0), heneicosanoic acid (C21:0), and tricosanoic acid (C23:0), between the treatment and control groups.

\section{Amino acid production}

Twenty-eight amino acids were detected in $C$. vulgaris cells (Table 3). Ornithine, lysine, and histidine levels increased in all treatment groups compared with controls. In the ceftazidime group, the levels of 7 and 12 amino acids increased and decreased, respectively, compared with the control; 7 and 17 amino acids increased and decreased in the GS group, respectively. In the combined ceftazidime and GS group, 4 amino acids increased and 24 decreased due to the synergistic effects of the antibiotics. Overall, significant differences in amino acid levels between the treatment and control groups were observed $(p<0.05)$.

\section{Discussion}

\section{Role of bacterial communities in culture}

Both ceftazidime and GS inhibited the proliferation of bacteria and changed the bacterial compositions in contaminated culture. Cyanobacteria, Bacteroidetes, and Proteobacteria were the main bacterial phyla in culture, likely because of their close interactions with $C$. vulgaris. Zhu et al. (2019) recognized that Bacteroidetes benefited the growth of C. vulgaris more than Proteobacteria and Cyanobacteria
Table 3 Fold changes of amino acids in experiments compared with control

\begin{tabular}{|c|c|c|c|c|c|c|}
\hline Component Name & Ceftazidime & $p$ value & GS & $p$ value & Ceftazidime + GS & $p$ value \\
\hline Taurine & 4.99 & $8.8 \mathrm{E}-06$ & 0.69 & 0.0328 & 3.90 & $6.3 \mathrm{E}-05$ \\
\hline Ornithine & 1.64 & 0.0003 & 3.31 & 7.4E-06 & 1.84 & 0.0124 \\
\hline Lysine & 1.48 & 0.0231 & 2.34 & $1.4 \mathrm{E}-05$ & 1.37 & 0.0424 \\
\hline Histidine & 1.14 & 0.8321 & 1.18 & 0.6232 & 1.36 & 0.0032 \\
\hline Putrescine & 0.82 & 0.4934 & 1.30 & 0.0342 & 0.85 & 0.0120 \\
\hline Threonine & 0.91 & 0.9280 & 1.01 & 0.9267 & 0.72 & 0.0533 \\
\hline Arginine & 0.77 & 0.7312 & 0.88 & 0.3829 & 0.69 & 0.4373 \\
\hline Glutamate & 0.88 & 0.0477 & 1.10 & 0.4722 & 0.68 & 0.0327 \\
\hline Glycine & 0.78 & 0.0342 & 1.21 & 0.5936 & 0.65 & 0.0015 \\
\hline Aspartate & 1.18 & 0.6123 & 1.12 & 0.6125 & 0.63 & 0.0024 \\
\hline Asparagine & 0.80 & 0.0731 & 1.00 & - & 0.62 & 0.0103 \\
\hline Isoleucine & 0.75 & 0.0338 & 0.82 & 0.0321 & 0.57 & 0.0036 \\
\hline Alanine & 0.70 & 0.0032 & 0.87 & 0.0423 & 0.56 & 0.0043 \\
\hline Cystine & 1.19 & 0.7352 & 0.57 & 0.0583 & 0.56 & 0.0057 \\
\hline Spermidine & 1.10 & 0.4821 & 1.34 & 0.0414 & 0.55 & 0.0056 \\
\hline Serine & 0.68 & 0.0324 & 0.82 & 0.0030 & 0.55 & 0.0051 \\
\hline Methionine & 0.55 & 0.0793 & 0.82 & 0.0432 & 0.53 & 0.0048 \\
\hline Tyrosine & 0.77 & 0.0383 & 0.79 & 0.0324 & 0.53 & 0.0073 \\
\hline Tryptophan & 0.57 & 0.0617 & 0.69 & 0.0426 & 0.51 & 0.0779 \\
\hline Valine & 0.68 & 0.0283 & 0.73 & 0.0722 & 0.51 & 0.0684 \\
\hline Hydroxyproline & 0.75 & 0.0023 & 0.82 & 0.0065 & 0.50 & 0.3022 \\
\hline Leucine & 0.58 & 0.0120 & 0.65 & 0.0153 & 0.46 & 0.0063 \\
\hline Citrulline & 0.53 & 0.0048 & 1.17 & 0.0024 & 0.38 & 0.0452 \\
\hline Cysteine & 0.70 & 0.0337 & 0.41 & 0.0399 & 0.37 & 0.4453 \\
\hline Phenylalanine & 0.41 & 0.0023 & 0.48 & 0.0010 & 0.36 & 0.0002 \\
\hline Proline & 0.37 & 0.0001 & 0.47 & 0.4320 & 0.32 & 0.0001 \\
\hline Choline & 0.39 & 0.0002 & 0.45 & 0.1423 & 0.32 & 0.0001 \\
\hline Glutamine & 0.42 & 0.0011 & 0.47 & 0.3213 & 0.28 & $1.1 \mathrm{E}-06$ \\
\hline
\end{tabular}

Six biological replicates and three technical replicates were conducted for amino acid analyses 
did. In particular, allelopathic interactions of cyanobacteria with C. vulgaris have been observed (Song et al. 2017). Indeed, ceftazidime and GS induced Proteobacteria to become the dominant bacterial phylum in algal culture, though Bacteroidetes showed the highest abundances in the combined antibiotic groups. Bacteroidetes may benefit the growth of $C$. vulgaris under the combined antibiotics. Thus, the combined ceftazidime and GS treatment may be an appropriate solution to avoid harmful bacteria but retain beneficial bacteria for the aseptic treatment of $C$. vulgaris.

\section{Effects of ceftazidime and GS on C. vulgaris}

In this study, ceftazidime inhibited $C$. vulgaris growth, whereas GS enhanced growth (Fig. 2). The inhibition caused by ceftazidime may be explained by the population of C. vulgaris being decreased because it was previously shown before that ceftazidime is able to reduce the $C$. pyrenoidosa population ( $\mathrm{Yu}$ et al. 2017). Although there are few reports discussing the interaction of GS with algae, many studies have reported that this antibiotic can affect algal growth and reproduction (González-Pleiter et al. 2013). In this study, the combination of ceftazidime and GS had different effects on the physiology of $C$. vulgaris compared with those caused by ceftazidime or GS alone. Similarly, a previous study reported that this combination of antibiotics might have synergistic effects on the growth of $C$. vulgaris (Wang et al. 2019). Such an effect was confirmed in our study, as downregulated DEGs in the combined ceftazidime and GS treatment were mapped to pathways of porphyrin and chlorophyll metabolism and carotenoid biosynthesis. Furthermore, the downregulation of gene expression related to pigment metabolism was in accordance with the decreased concentration of chlorophyll and carotenoids in C. vulgaris. Despite no significant differences in $\mathrm{Chl} a$, Chl $b$, and carotenoid contents between the combined ceftazidime and GS and control groups, some genes related to chlorophyll and carotenoids were markably regulated by the combined ceftazidime and GS treatment.

\section{Antibiotics regulated fatty acid biosynthesis and degradation}

Ceftazidime and GS caused notable changes in the expression levels of DEGs enriched in fatty acid biosynthesis and degradation pathways, even the ceftazidime and GS combination, which had a small effect on the growth rate and the concentrations of chlorophyll and carotenoid in the algae. In this work, downregulated DEGs were mapped to the pathway of fatty acid biosynthesis (Supplemental Fig. S8). In general, the first step of fatty acid biosynthesis is performed by acetyl-CoA carboxylase complex which catalyses the irreversible carboxylation of acetyl-CoA to produce malonyl-CoA (Bilbao et al. 2017). The downregulated gene $A c c B$ for acetyl-CoA carboxylase biotin carboxyl carrier protein would cause a decline in fatty acid biosynthesis. The downregulated gene $\mathrm{FabF/FabH}$ related to 3-oxoacyl-coenzyme A synthesis controls the condensation of acetyl-coenzyme A to acetoacetyl coenzyme A (Young et al. 2006). In contrast, in this study, the pathway of fatty acid degradation was enriched by upregulated DEGs. Both AcoX1/AvoX3 encoding acyl-CoA oxidase and $A c c D$ encoding acyl-CoA dehydrogenase are involved in fatty acid degradation (Kong et al. 2017), and both were upregulated in the combined ceftazidime and GS group, indicating enhanced degradation of fatty acids.

Intracellular variations in fatty acids were quantified by gas chromatography-mass spectrometry, and fatty acids decreased in the treatment groups compared with the control by over $50 \%$, suggesting that ceftazidime and GS inhibit fatty acid biosynthesis. The contents of oleic acid (C18:1N9) and $\alpha$ linolenic acid $(\mathrm{C} 18: 3 \mathrm{~N} 3)$ also decreased in the combination group, as demonstrated by the downregulation of FatA, which is involved in fatty acyl-acyl carrier protein thioesterase A production (Chen et al. 2012). The upregulated genes Ter/ $T s c / C e r 10$ encode enzymes for hexanoic acid synthesis and were associated with an increasing concentration of hexanoic acid (C6:0) with the combined ceftazidime and GS treatment.

\section{Antibiotic-regulated amino acid metabolism}

The amino acid composition of algae is an important aspect regarding their use for biofuel production (Sakarika and Kornaros 2019). The backbone of amino acids is mainly obtained from fructose-6-phosphate, phosphoenolpyruvate, and the citric acid cycle (McCusker et al. 2014). Ceftazidime and GS induced various changes in the expression levels of genes related to fructose-6-phosphate and phosphoenolpyruvate metabolism and the citric acid cycle (Supplementary Fig. 8). In this study, the upregulated DEGs in the ceftazidime group showed enrichment in the KEGG pathway of valine, leucine, and isoleucine biosynthesis, whereas enrichment in their degradation pathway was found for upregulated and downregulated DEGs in the GS group. In addition, upregulated and downregulated DEGs in the combined ceftazidime and GS group were associated with phenylalanine, tyrosine, and tryptophan biosynthesis pathway. Therefore, ceftazidime, GS, and their combination might have strong effects on the various amino acid productions in C. vulgaris.

Ceftazidime and/or GS is able to regulate the concentration of intracellular amino acids in algal cells. For instance, an enhanced histidine level was found to be a response to upregulation of $A l d H$, and the encoded enzyme is involved in aldehyde metabolism (Brocker et al. 2013). In our study, glutamine and arginine levels decreased in the combined ceftazidime and GS group (Table 3), which was probably caused by downregulation of GlnA and SpeC/SpecF, which encode glutamine and arginine synthetases (Chandra et al. 2010). The 
results suggest that appropriate application of ceftazidime and GS can regulate specific intracellular amino acid production in C. vulgaris.

In conclusion, the results indicate that ceftazidime and/or GS reduce bacterial infection in algal culture; the combination of antibiotics achieved the highest inhibition of bacterial abundance with the lowest impact on C. vulgaris growth. Simultaneously, chlorophyll production, carotenoid biosynthesis, fatty acid biosynthesis, and amino acid production in algal cells were remarkably affected by ceftazidime and/or GS. Transcription analysis reflected the activities of the antibiotics in detail, and the results provide clues to the physiological changes observed in C. vulgaris. In total, the recovery of physiological metabolites should be considered when selecting antibiotics for bacterial removal in algal strain applications.

Authors' contributions All authors have contributed to the manuscript. WWJ wrote and prepared the figures and tables. All authors revised and approved the final manuscript.

Funding information This study was funded by the National Natural Science Foundation of China $(31600370 ; 41373100)$ and Science and Technology Plan of Yantai City (2018ZHGY080). Additional support was provided by the STS of the Chinese Academy of Sciences (KFJSTS-QYZX-057).

Data availability The raw data of the de novo transcriptome have been submitted to NCBI; other data and materials are available from the corresponding author.

\section{Compliance with ethical standards}

Conflict of interest The authors declare that they have no conflict of interest.

Ethical approval This article does not contain any studies with animals performed by any of the authors.

\section{References}

Anto S, Mukherjee SS, Muthappa R, Mathimani T, Deviram G, Kumar SS, Verma TN, Pugazhendhi A (2020) Algae as green energy reserve: technological outlook on biofuel production. Chemosphere 242:125079. https://doi.org/10.1016/j.chemosphere.2019.125079

Bai Z, Qi T, Liu Y, Wu Z, Ma L, Liu W, Cao Y, Bao Y, Fu C (2018) Alteration of S-adenosylhomocysteine levels affects lignin biosynthesis in switchgrass. Plant Biotechnol J 16:2016-2026. https://doi. org/10.1111/pbi.12935

Barbosa ADS, Cardozo ML, Dib LV, Fonseca NBM, Uchôa CMA, Pereira BOM, Amendoeira MRR (2018) Comparative study of three xenic media culture for cultivation of Balantidium coli strains. Rev Bras Parasitol Vet 27:20-26. https://doi.org/10.1590/S198429612017075

Bilbao PS, Salvador GAP, Leonardi I (2017) Fatty acids from microalgae: targeting the accumulation of triacylglycerides. InTech, London
Brocker C, Vasiliou M, Carpenter S, Carpenter C, Zhang Y, Wang X, Kotchoni SO, Wood AJ, Kirch HH, Kopečný D, Nebert DW, Vasiliou V (2013) Aldehyde dehydrogenase $(A L D H)$ superfamily in plants: gene nomenclature and comparative genomics. Planta 237:189-210. https://doi.org/10.1007/s00425-012-1749-0

Breuer G, Evers WA, de Vree JH, Kleinegris DM, Martens DE, Wijffels RH, Lamers PP (2013) Analysis of fatty acid content and composition in microalgae. J Vis Exp 80:50628. https://doi.org/10.3791/ 50628

Caporaso JG, Kuczynski J, Stombaugh J, Bittinger K, Bushman FD, Costello EK, Fierer N, Peña AG, Goodrich JK, Gordon JI, Huttley GA, Kelley ST, Knights D, Koenig JE, Ley RE, Lozupone CA, McDonald D, Muegge BD, Pirrung M, Reeder J, Sevinsky JR, Turnbaugh PJ, Walters WA, Widmann J, Yatsunenko T, Zaneveld J, Knight R (2010) QIIME allows analysis of high-throughput community sequencing data. Nat Methods 7:335-336. https://doi.org/ 10.1038/nmeth.f.303

Chandra H, Basir SF, Gupta M, Banerjee N (2010) Glutamine synthetase encoded by $g \ln A-1$ is necessary for cell wall resistance and pathogenicity of Mycobacterium bovis. Microbiology 156:3669-3677. https://doi.org/10.1099/mic.0.043828-0

Chapman IJ, Franklin DJ, Turner AD, McCarthy EJA, Esteban GF (2019) Predator-prey interactions between the ciliate Blepharisma americanum and toxic (Microcystis spp.) and non-toxic (Chlorella vulgaris, Microcystis sp.) photosynthetic microbes. Aquat Microb Ecol 83:211-224. https://doi.org/10.3354/ame01913

Chen G, Peng ZY, Shan L, Xuan N, Tang GY, Zhang Y, Li L, He QF, Bi YP (2012) Cloning of acyl-ACP thioesterase FatA from Arachis hypogaea L. and its expression in Escherichia coli. J Biomed Biotechnol 2012:652579. https://doi.org/10.1155/2012/652579

Cirri E, Pohnert G (2019) Algae-bacteria interactions that balance the planktonic microbiome. New Phytol 223:100-106. https://doi.org/ 10.1111/nph.15765

Deviram G, Mathimani T, Anto S, Ahamed TS, Ananth DA, Pugazhendhi A (2020) Applications of microalgal and cyanobacterial biomass on a way to safe, cleaner and a sustainable environment. J Clean Prod 253:119770. https://doi.org/10.1016/j. jclepro.2019.119770

Dias E, Oliveira M, Jones-Dias D, Vasconcelos V, Ferreira E, Manageiro V, Caniça M (2015) Assessing the antibiotic susceptibility of freshwater Cyanobacteria spp. Front Microbiol 6:799. https://doi.org/10. 3389/fmicb.2015.00799

Edgar R (2013) UPARSE: highly accurate OTU sequences from microbial amplicon reads. Nat Methods 10:996-998. https://doi.org/10. 1038/nmeth.2604

Fu L, Huang T, Wang S, Wang XH, Su LM, Li C, Zhao YH (2017) Toxicity of 13 different antibiotics towards freshwater green algae Pseudokirchneriella subcapitata and their modes of action. Chemosphere 168:217-222. https://doi.org/10.1016/j. chemosphere.2016.10.043

Gao Z, Zhao Z, Tang W (2018) Dreamseq: an improved method for analyzing differentially expressed genes in rna-seq data. Front Genet 30. https://doi.org/10.3389/fgene.2018.00588

González-Pleiter M, Gonzalo S, Rodea-Palomares I, Leganés F, Rosal R, Boltes K, Marco E, Fernández-Piñas F (2013) Toxicity of five antibiotics and their mixtures towards photosynthetic aquatic organisms: implications for environmental risk assessment. Water Res 47:2050-2064. https://doi.org/10.1016/j.watres.2013.01.020

Gordon GC, Pfleger BF (2018) Regulatory tools for controlling gene expression in Cyanobacteria. Adv Exp Med Biol 1080:281-315. https://doi.org/10.1007/978-981-13-0854-3_12

Haas BJ, Gevers D, Earl AM, Feldgarden M, Ward DV, Giannoukos G, Ciulla D, Tabbaa D, Highlander SK, Sodergren E, Methé B, TZ DS, Human Microbiome Consortium, Petrosino JF, Knight R, Birren BW (2011) Chimeric 16S rRNA sequence formation and detection 
in Sanger and 454-pyrosequenced PCR amplicons. Genome Res 21: 494-504. https://doi.org/10.1101/gr.112730.110

He Y, Ma Y, Du Y, Shen SD (2018) Differential gene expression for carotenoid biosynthesis in a green alga Ulva prolifera based on transcriptome analysis. BMC Genomics 19:916. https://doi.org/10. 1186/s12864-018-5337-y

Kanehisa M, Araki M, Goto S, Hattori M, Hirakawa M, Itoh M, Katayama T, Kawashima S, Okuda S, Tokimatsu T (2007) KEGG for linking genomes to life and the environment. Nucleic Acids Res 36(suppl_1):D480-D484. https://doi.org/10.1093/nar/gkm882

Kazamia E, Aldridge DC, Smith AG (2012) Synthetic ecology-a way forward for sustainable algal biofuel production? J Biotechnol 162: 163-169. https://doi.org/10.1016/j.jbiotec.2012.03.022

Kong F, Liang Y, Légeret B, Beyly-Adriano A, Blangy S, Haslam RP, Napier JA, Beisson F, Peltier G, Li Beisson Y (2017) Chlamydomonas carries out fatty acid $\beta$-oxidation in ancestral peroxisomes using a bona fide acyl-CoA oxidase. Plant J 90:358-371. https://doi.org/10.1111/tpj.13498

Lopez BR, Palacios OA, Bashan Y, Hernández-Sandoval FE, de Bashan LE (2019) Riboflavin and lumichrome exuded by the bacterium Azospirillum brasilense promote growth and changes in metabolites in Chlorella sorokiniana under autotrophic conditions. Algal Res 44:101696. https://doi.org/10.1016/j.algal.2019.101696

Mathimani T, Baldinelli A, Rajendran K, Prabakar D, Matheswaran M, van Leeuwen RP, Pugazhendhi A (2019) Review on cultivation and thermochemical conversion of microalgae to fuels and chemicals: process evaluation and knowledge gaps. J Clean Prod 208:10531064. https://doi.org/10.1016/j.jclepro.2018.10.096

Mao X, Cai T, Olyarchuk JG, Wei L (2005) Automated genome annotation and pathway identification using the KEGG Orthology (KO) as a controlled vocabulary. Bioinformatics 21:3787-3793. https://doi. org/10.1093/bioinformatics/bti430

McCusker S, Buff PR, Yu Z, Fascetti AJ (2014) Amino acid content of selected plant, algae and insect species: a search for alternative protein sources for use in pet foods. J Nutr Sci 3:e39. https://doi.org/10. $1017 /$ jns.2014.33

Nguyen TDP, Nguyen DH, Lim JW, Chang C-K, Leong HY, Tran TNT, $\mathrm{Vu}$ TBH, Nguyen TTC, Show PL (2019) Investigation of the relationship between bacteria growth and lipid production cultivating of microalgae Chlorella vulgaris in seafood wastewater. Energies 12: 2282. https://doi.org/10.3390/en12122282

Quast C, Pruesse E, Yilmaz P, Gerken J, Schweer T, Yarza P, Peplies J, Glöckner FO (2013) The SILVA ribosomal RNA gene database project: improved data processing and web-based tools. Nucl Acids Res 41:D590-D596. https://doi.org/10.1093/nar/gks1219

Rognes T, Flouri T, Nichols B, Quince C, Mahé F (2016) VSEARCH: a versatile open source tool for metagenomics. Peer J 18:e2584. https://doi.org/10.7717/peerj.2584

Sakarika M, Kornaros M (2019) Chlorella vulgaris as a green biofuel factory: comparison between biodiesel, biogas and combustible biomass production. Bioresour Technol 273:237-243. https://doi.org/ 10.1016/j.biortech.2018.11.017

Sharma J, Kumar SS, Bishnoi NR, Pugazhendhi A (2018) Enhancement of lipid production from algal biomass through various growth parameters. J Mol Liq 269:712-720. https://doi.org/10.1016/j. molliq.2018.08.103

Song H, Lavoie M, Fan X, Tan H, Liu G, Xu P, Fu Z, Paerl HW, Qian H (2017) Allelopathic interactions of linoleic acid and nitric oxide increase the competitive ability of Microcystis aeruginosa. ISME J11:1865-1876. https://doi.org/10.1038/ismej.2017.45

Sun J, Yang P, Li N, Zhao M, Zhang X, Zhang Y, Yuan Y, Lu X, Lu X (2020) Extraction of photosynthetic electron from mixed photosynthetic consortium of bacteria and algae towards sustainable bioelectrical energy harvesting. Electrochim Acta 336:135710. https://doi. org/10.1016/j.electacta.2020.135710

$\mathrm{Vu}$ CHT, Lee HG, Chang YK, Oh HM (2018) Axenic cultures for microalgal biotechnology: establishment, assessment, maintenance, and applications. Biotechnol Adv 36:380-396. https://doi.org/10. 1016/j.biotechadv.2017.12.018

Wang H, Hill RT, Zheng T, Hu X, Wang B (2016) Effects of bacterial communities on biofuel-producing microalgae: stimulation, inhibition and harvesting. Crit Rev Biotechnol 36:341-352. https://doi. org/10.3109/07388551.2014.961402

Wang GX, Zhang Q, Li JL, Chen XY, Lang QL, Kuang SP (2019) Combined effects of erythromycin and enrofloxacin on antioxidant enzymes and photosynthesis-related gene transcription in Chlorella vulgaris. Aquat Toxicol 212:138-145. https://doi.org/10.1016/j. aquatox.2019.05.004

Wang WJ, Sheng YQ (2019) Pseudomonas sp. strain WJ04 enhances current generation of Synechocystis sp. PCC6803 in photomicrobial fuel cells. Algal Res 40:101490. https://doi.org/10.1016/j.algal. 2019.101490

Xu G, Cai W, Gao W, Liu C (2016) A novel glucuronosyltransferase has an unprecedented ability to catalyse continuous two-step glucuronosylation of glycyrrhetinic acid to yield glycyrrhizin. New Phytol 212:123-135. https://doi.org/10.1111/nph.14039

Young K, Jayasuriya H, Ondeyka JG, Herath K, Zhang C, Kodali S, Galgoci A, Painter R, Brown-Driver V, Yamamoto R, Silver LL, Zheng Y, Ventura JI, Sigmund J, Ha S, Basilio A, Vicente F, Tormo JR, Pelaez F, Youngman P, Cully D, Barrett JF, Schmatz D, Singh $\mathrm{SB}$, Wang J (2006) Discovery of $\mathrm{FabH} / \mathrm{FabF}$ inhibitors from natural products. Antimicrob Agents Chemother 50:519-526. https://doi. org/10.1128/AAC.50.2.519-526.2006

Yu Y, Zhou Y, Wang Z, Torres OL, Guo R, Chen J (2017) Investigation of the removal mechanism of antibiotic ceftazidime by green algae and subsequent microbic impact assessment. Sci Rep-UK 7:4168. https://doi.org/10.1038/s41598-017-04128-3

Zhu SN, Feng SR, Xu ZB, Qin L, Shang CH, Feng PZ, Wang ZM, Yuan ZH (2019) Cultivation of Chlorella vulgaris on unsterilized dairyderived liquid digestate for simultaneous biofuels feedstock production and pollutant removal. Bioresour Technol 285:121353. https:// doi.org/10.1016/j.biortech.2019.121353

Publisher's note Springer Nature remains neutral with regard to jurisdictional claims in published maps and institutional affiliations. 